\title{
A New Placement and Integration Method of UPQC to Improve the Power Quality in DG Network
}

\author{
Shafiuzzaman K. Khadem \\ Technological University Dublin \\ Malabika Basu \\ Technological University Dublin, mbasu@tudublin.ie \\ Michael Conlon \\ Technological University Dublin, michael.conlon@tudublin.ie
}

Follow this and additional works at: https://arrow.tudublin.ie/engscheleart

Part of the Electrical and Electronics Commons

\section{Recommended Citation}

Khadem, S.K.; Basu, M.; Conlon, M.F., "A new placement and integration method of UPQC to improve the power quality in DG network," Power Engineering Conference (UPEC), 2013 48th International Universities' , vol., no., pp.1,6, 2-5 Sept. 2013 doi: 10.1109/UPEC.2013.6715007

This Conference Paper is brought to you for free and open access by the School of Electrical and Electronic Engineering at ARROW@TU Dublin. It has been accepted for inclusion in Conference papers by an authorized administrator of ARROW@TU Dublin. For more information, please contact arrow.admin@tudublin.ie, aisling.coyne@tudublin.ie,gerard.connolly@tudublin.ie.

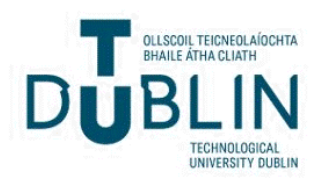




\section{A new placement and integration method of UPQC to improve the power quality in DG network}

\author{
Shafiuzzaman K Khadem \\ Member IEEE \\ School of Electrical \& \\ Electronic Engineering, Dublin \\ Institute of Technology, Ireland \\ E-mail: skkhadem@gmail.com
}

\author{
Malabika Basu \\ Member IEEE \\ School of Electrical \& Electronic \\ Engineering, Dublin Institute of \\ Technology, Ireland \\ E-mail:malabika.basu@dit.ie
}

\author{
Michael F Conlon \\ Member IEEE \\ School of Electrical \& \\ Electronic Engineering, Dublin \\ Institute of Technology, Ireland \\ E-mail: michael.conlon@dit.ie
}

\begin{abstract}
A new proposal for the placement and integration of UPQC in DG connected microgrid/micro generation $(\mu G)$ system has been presented here. DG converters (with storage), the load and shunt part of the UPQC will be placed at or after the PCC. The series part of the UPQC will be placed before the PCC and in series with the grid. DC link can be connected to the storage system also. Hence, it is termed $U P Q C \mu_{G}$. The advantages of the proposed $U P Q C \mu_{G}$ over the normal $U P Q C$ are to compensate voltage interruptions in addition to voltage sags / swells, harmonic and reactive power compensation in the interconnected mode. The DG Converter with storage will supply the active power only and the shunt part of the UPQC will compensate the reactive and harmonic power of the load in the islanding mode. Therefore, the system can work both in interconnected and islanded mode. DG Converter does not require to be disconnected during the voltage disturbance. In all conditions, DG Converter will only provide the active power to the load and grid. Thus it will reduce the control complexity of the DG converter as well as improve the PQ of the network.
\end{abstract}

Index Terms-- Unified Power Quality Compensator, Microgrid, Power Quality, Distributed Generation, Smart Grid

\section{INTRODUCTION}

As a part of the integration of the UPQC in a DG connected $\mathrm{grid} / \mu \mathrm{G}$ system, research to date has been carried out on two techniques; i) (DG-UPQC) DC-linked $_{\text {and ii) (DG-UPQC) }}$ SeparatedThe pros and cons of these configurations are given details in [1]. The main problems for the configurations are i) the control complexity for active power transfer, ii) inability to provide harmonic and reactive power compensation during the islanded mode and iii) difficulty in the capacity enhancement in multi-level or multi-module mode. On the other hand, DG converter shall detect the unintentional islanding and cease to energize the islanded area within two seconds of the formation of an island [2]. One of the reasons is that the controller of the grid-tie DG converter is designed to provide only the active power to the load and grid in the interconnected mode. For a seamless power transfer between the grid-connected operation and islanded mode, that is transfer between the current and voltage control modes of operation along with the robustness against the islanding detection and reconnection delays, research on hybrid control converter is underway [3]. Clearly this will further increase the control complexity of the converter. However, the DG converter needs to be disconnected or to change its control strategy to work in the islanding mode after detecting the unintentional islanding. To extend the operational flexibility and to improve the power quality in grid connected $\mu \mathrm{G}$ systems, integration technique of UPQC have been proposed here. The $\mu \mathrm{G}$ system (with storage), the load and shunt part of the UPQC $\left(\mathrm{APF}_{\mathrm{sh}}\right)$ will be placed at or after the PCC. The series part of the UPQC $\left(\mathrm{APF}_{\mathrm{se}}\right)$ will be placed before the PCC and in series with the grid. DC link can be connected to the storage system also. Hence, it is termed $U P Q C \mu_{\mathrm{G}}$. The UPQC current sensor, for reactive and harmonic power compensation, will measure only the load current. The main advantages of the proposed $\mathrm{UPQC} \mu_{\mathrm{G}}$ over the conventional UPQC are as follow.

- $\quad \mathrm{UPQC}_{\mathrm{G}}$ will compensate voltage interruptions in addition to voltage sags/swells, harmonic and reactive power compensation in the interconnected mode. Therefore, the DG converter can still be connected to the system during the voltage sag/interrupt condition. Thus it will extend the operational flexibility of the DG converters in the $\mu \mathrm{G}$ system.

- It will also compensate the reactive and harmonic $(\mathrm{QH})$ power of the load in islanded mode.

- Due to the integration technique, the DG converter will then be more flexible to be islanded.

Both in the current and voltage control modes, the $\mu \mathrm{G}$ system will provide only the active power to the load. Therefore, it can reduce the control complexity of the converter

\section{WORKING PRINCIPLE}

The integration technique of the proposed $U P Q C \mu_{G}$ to a grid connected and DG integrated $\mu \mathrm{G}$ system is presented in Fig 1(a). The working principle during the interconnected and islanded mode for this configuration is shown in Fig 1(b, c).

\section{A. Interconnected mode}

In this mode, as shown in Fig 1(b), the following will happen.

i. The DG source will deliver only the fundamental active power to the grid, storage and load.

ii. The $\mathrm{APF}_{\mathrm{sh}}$ will compensate the reactive and harmonic $(\mathrm{QH})$ power of the non-linear load to keep the THD at the PCC within the IEEE standard limit.

iii. Voltage sag/swell/interruption can be compensated by the active power from the grid/storage through the $\mathrm{APF}_{\mathrm{se}}$. DG 
converter will not sense any kind of voltage disturbance at the PCC and hence will remain connected in any condition.

iv. If the voltage interruption/black out occurs then UPQC will send a signal to the DG converter to be islanded.

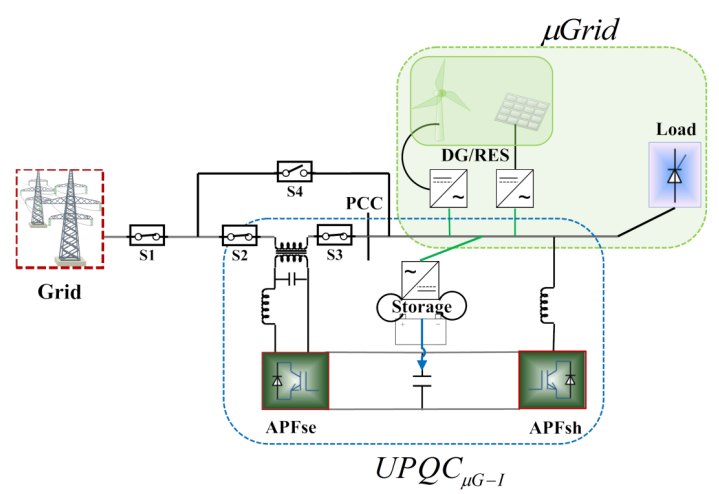

(a)

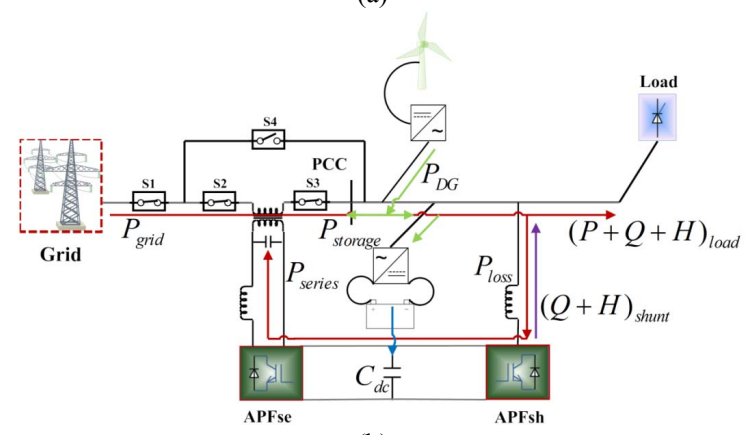

(b)

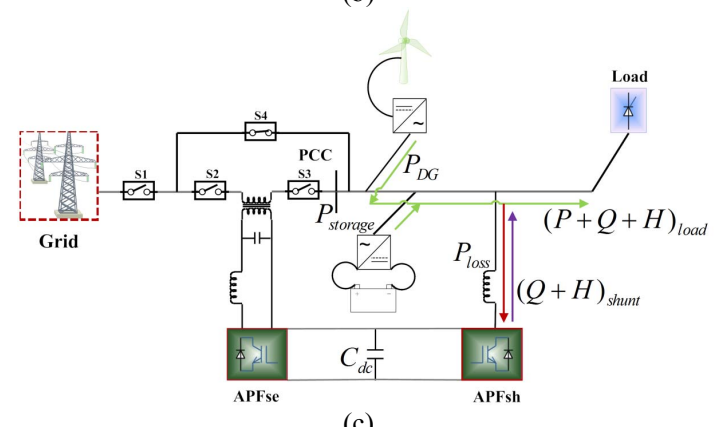

(c)

Fig 1: (a) Integration technique of the $\mathrm{UPQC}_{\mu \mathrm{G}}$; (b) Working principle in interconnected and (c) islanded mode

\section{B. Islanded mode}

In this case, as shown in Fig 1(c), the following will occur. i. The $\mathrm{APF}_{\mathrm{se}}$ will be disconnected during the grid failure and DG converter will remain connected and maintain the required voltage at $\mathrm{PCC}$.

ii. The $\mathrm{APF}_{\mathrm{sh}}$ will still compensate the non-active power of the non-linear load to provide or maintain undistorted current at PCC for other linear loads (if any).

iii. Therefore, DG converter (with storage) will deliver only the active power and hence does not need to be disconnected from the system.

iv. The $\mathrm{APF}_{\mathrm{se}}$ will be reconnected once the grid power is available.

From Fig 1, it is clear that the $\mathrm{UPQC}_{\mu \mathrm{G}}$ requires four switches. As the synchronization and reconnection control are part of the DG converter, after synchronization the converter is directly reconnected (through $\mathrm{S} 4$ and $\mathrm{S} 1$ ) to the grid and then sends an activation signal to $\mathrm{UPQC}_{\mu \mathrm{G}}$ to prepare for reconnection. After a suitable time, $\mathrm{APF}_{\mathrm{se}}$ of $\mathrm{UPQC}_{\mu \mathrm{G}}$ reconnects through S2 and S3 (by deactivated S4). A detail of the switching mechanism is discussed in the controller design section.

\section{CONTROLLER DESIGN}

The block diagram of the proposed $\mathrm{UPQC} \mu_{\mathrm{G}}$ Controller is shown in Fig 2. It has the same basic functionality as the UPQC controller except for the additional signal generation for islanding detection technique and reconnection capabilities. A communication channel between the proposed $\mathrm{UPQC}_{\mu \mathrm{G}}$ and the $\mu \mathrm{G}$ is also required for the detection of islanding and reconnection. This signal generation are based on the sag/swell/interrupt/supply failure conditions. This task is performed in Level 2 (secondary control) of the hierarchical control [4]. Level 1 deals with the primary control of the series and shunt parts of the UPQC to perform their basic functions in the interconnected and the islanded mode. The overall integration technique and control strategy are to improve the power quality during interconnected and islanded modes. This involves detecting islanding and then ensuring that the DG converter remains connected and supplying active power to the load. This reduces the control complexity of the converter as well as the power failure possibility in the islanded mode. As the signal generation for Islanding detection (Sig-IsD) and Synchronization for Reconnection (Sig-SynRec) are new in UPQC therefore, these have been described in details.

\section{A. Sig-IsD}

In order to ensure the reliable and safe transfer of electrical energy to the grid and load during the interconnected mode, all DG systems should comply with a series of standard requirements given in the international regulations [5]. Considering the future trends towards the smart $\mu \mathrm{G}$ operation in connection with the distribution grid, the capability of (i) maintaining connection during grid fault condition, (ii) automatically detecting the islanded condition and (iii) reconnecting after the grid fault should be an important feature of the $\mu \mathrm{G}$ system. In that case, the placement of $\mathrm{APF}_{\mathrm{se}}$ in the proposed integration method of the system will play an important role by extending the operational flexibility of the DG converter in the $\mu \mathrm{G}$ system.

In addition to the islanding detection, changing the controlling strategy from current to voltage control may result in serious voltage deviations and it becomes severe when the islanding detection is delayed in the case of hierarchical control [6]. Therefore seamless voltage transfer control between the grid-connected and isolated controlled modes is very important $[7,8]$ and it increases the control complexity of the $\mu \mathrm{G}$ converters.

In the case of power quality problems, it is reported that more than $95 \%$ of voltage sags can be compensated by injecting a voltage of up to $60 \%$ of the nominal voltage, with 
a maximum duration of 30 cycles [9]. Therefore, based on the islanding detection requirement and sag/swell or other voltage disturbance compensation, a signal is generated for the islanding detection (Sig-IsD) in the proposed $\mathrm{UPQC}_{\mu \mathrm{G}}$ to transfer it to the DG converter. As the $\mathrm{APF}_{\mathrm{se}}$ takes the responsibility for compensating voltage sag/swell/unbalance disturbances (depending on the controller), IsD algorithm in DC converter can be quite flexible and simple.

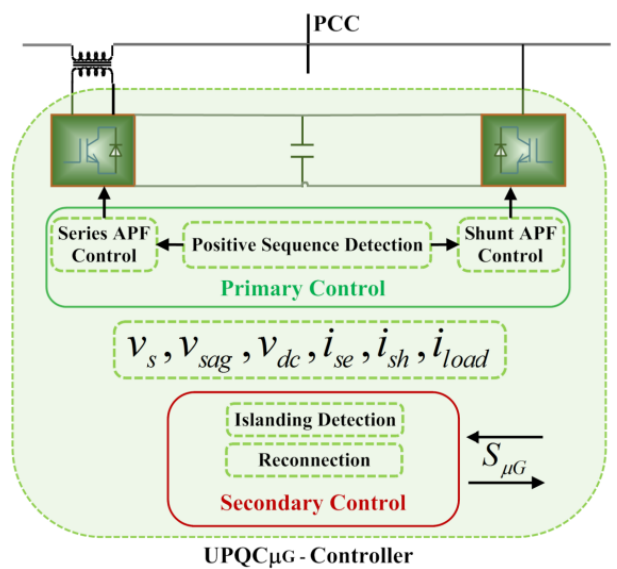

Fig 2: Block diagram of proposed $\mathrm{UPQC}_{\mu \mathrm{G}}$ Controller

Fig 3 shows the algorithm (with an example) that has been used to detect the islanding condition to operate the $\mathrm{UPQC}_{\mathrm{\mu G}}$ in the islanded mode. The voltage at PCC is taken here as the reference and it is always in phase with the source and the DG converter, the difference between the $V_{\text {pcc-ref }}(\mathrm{pu})$ and $V_{s}(\mathrm{pu})$ is $V_{\text {error }}$. This error is then compared with the pre-set values $(0.1$ to 0.9$)$ and a waiting period (user defined $n$ number of cycles) is used to determine the sag/interrupt/islanding condition. In this example, (i) if $V_{\text {error }}$ is less than or equal to 0.6 , then $60 \%$ sag will be compensated for up to 50 cycles; (ii) if $V_{\text {error }}$ is in between 0.6 to 0.9 , then compensation will be for 30 cycles; (iii) otherwise (if $V_{\text {error }} \geq 0.9$ ) it will be interrupt/black out for islanding after 1 cycle.

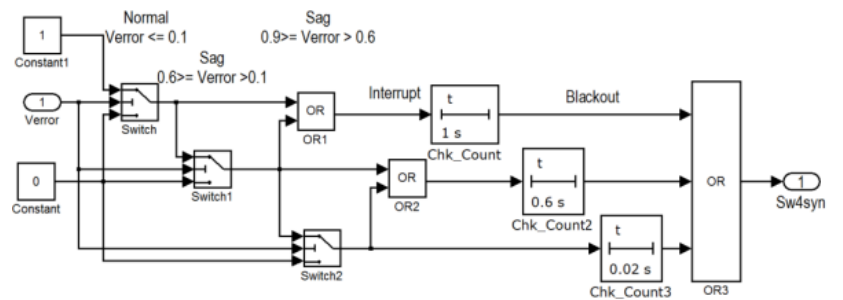

Fig 3: Signal generation for Islanding detection (Sig-IsD) method in simulink

This signal generation method is simple and can be adjusted for any time length and $V_{\text {error }}$ condition. Thus the flexibility of time and control for compensating the sag can be achieved before islanding. As the seamless voltage transfer from grid connected to isolated mode is one of the critical tasks in transition period, the transfer will be completed at the zero crossing position of the $\mathrm{APF}_{\text {se }}$. Therefore, no voltage fluctuation or abrupt conditions will occur.

\section{B. Sig-SynRec}

Once the grid system is restored, the $\mu \mathrm{G}$ may be reconnected to the main grid and return to its pre-disturbance condition. A smooth reconnection can be achieved when the difference between the voltage magnitude, phase and frequency of the two buses are minimized or close to zero.

In the case of the $\mathrm{UPQC}_{\mu \mathrm{G}}$, the synchronization for reconnection is done by the DG converter. Once the voltage magnitude, phase angle and frequency differences are within the pre-defined range or are close to zero, then reconnection is made through S4 and $\mathrm{S} 1$ as shown in Fig 1. The $\mu \mathrm{G}$ control system then sends a signal $S_{\mu G-R}$ to the $\mathrm{UPQC}_{\mu \mathrm{G}}$. The $\mathrm{APF}_{\mathrm{se}}$ is then activated and switches $\mathrm{S} 2$ and $\mathrm{S} 3$ are reconnected to the system by deactivating $\mathrm{S} 4$. This switching transition is controlled and performed at a zero crossing condition of $V_{s}$. As an example, Fig 4(a) shows a simple synchronization method for reconnection and $S_{\mu G-R}$ is the signal generated by the DG converter. This signal is activated when the phase difference between the utility $\left(V_{s}\right)$ and PCC are within 2 deg in phase and corresponding voltage amplitude difference is within $11.24 \mathrm{~V}$. These are observed at a zero crossing of $V_{s}$. Fig 4(b) shows the reconnection method of $\mathrm{APF}_{\mathrm{se}}$ for the $\mathrm{UPQC}_{\mu \mathrm{G}}$. The activated $S_{\mu G-R}$ signal is taken from the $\mu \mathrm{G}$ and passed through a S-R Flip Flop to generate the active signal (Swsesyn) for $\mathrm{APF}_{\mathrm{se}}$ at the $V_{s}$ zero crossing condition. This Swsesyn signal is then XOR to the Sw4syn (as shown in Fig 3 ) to generate the real activation signal for the $\mathrm{APF}_{\mathrm{se}}$.

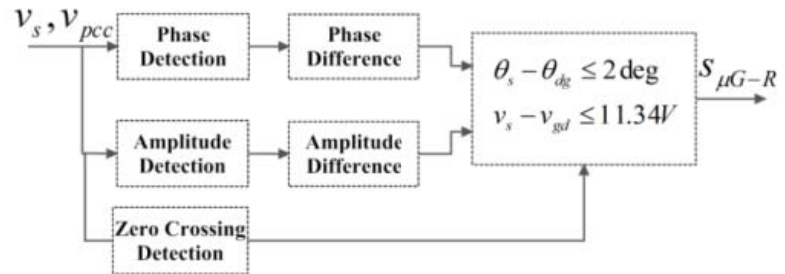

(a)

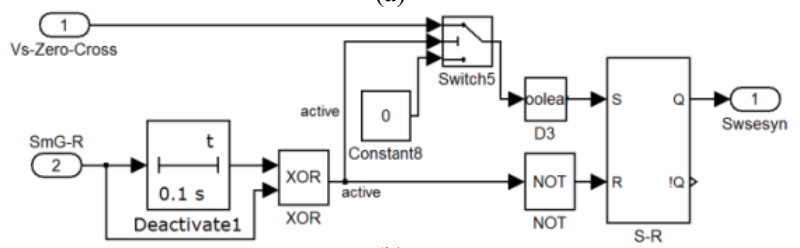

(b)

Fig 4: (a) Synchronization method and (b) Sig-SynRec method for $\mathrm{UPQC}_{\mu \mathrm{G}}$

\section{SimULATION STUDY}

A 3-phase, 3-wire active distribution network $\left(230 \mathrm{~V}_{\mathrm{L}-\mathrm{N}}\right)$ with the proposed $\mathrm{UPQC}_{\mu \mathrm{G}}$ and $\mu \mathrm{G}$, as shown in Fig 1, has been developed in the MATLAB environment. The system specifications are as follow; $\mathrm{UPQC}_{\mu \mathrm{G}}$ (capability: $100 \% \mathrm{sag}$ and 100Amax harmonic current compensation) and the $\mu \mathrm{G}$ (Load: 200Amax with harmonic 100Amax; DG: 0.5 to 1.5 times of load fundamentals). Details of the performance with the simulation results are given below. All the simulations have been performed for up to $2 \mathrm{sec}$. Table 1 shows the timeline for the respective operating conditions. 
TABLE 1

TIMELINE OF THE OPERATING CONDITIONS

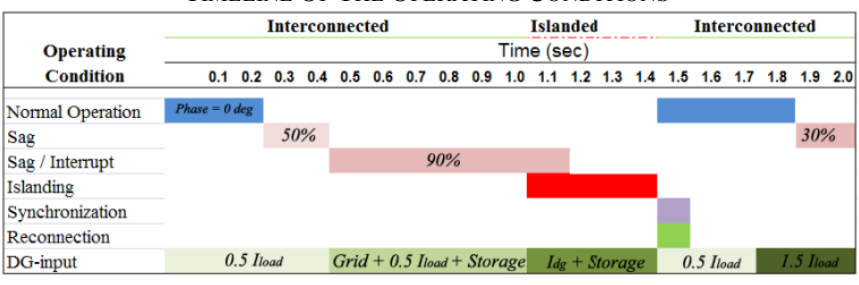

Based on the integration method and signal generation for islanding detection and the reconnection method, Fig 5(a) shows the switch positions ( 0 for open and 1 for close) during the operation from 0 to $2 \mathrm{sec}$ where both the interconnected and islanded modes are observed. The performance of the proposed $\mathrm{UPQC}_{\mu \mathrm{G}}$ for voltage sag compensation is shown in Fig 5(b) and harmonic current compensation is shown in Fig 5(c) based on the Table 1. Performance during the reverse current flow due to the high penetration of DG is also shown by the red circle in Fig 5(c). Details of the performance at different conditions are discussed below. Generally waveforms are shown for phase A only.

\section{A. Interconnected Mode}

Depending on the power availability, the DG source can supply power to the load and grid, and therefore bydirectional power flow can occur. Hence, the performance of the proposed UPQC should be observed in both cases. For a better understanding, according to the direction of power flow, operation in the interconnected mode can be divided into two parts: (1) forward-flow mode and (2) reverse-flow mode.

\section{a. Forward-flow mode}

In this case, the available DG power is less than the required load demand. Therefore, the utility supplies rest of the power to the load which is not met by the DG supply. Fig 6 shows the performance of the $\mathrm{APF}_{\mathrm{sh}}$ in compensating the reactive and harmonic current generated by the load. As is mentioned in the timeline table, the DG unit supplies $0.5 I_{\text {loadf }}$ (half of load fundamental in current control mode) during this time frame. Therefore the remainder of the current is supplied by the utility grid and storage. During a $90 \%$ sag condition, the total power for the load demand is still met by the $\mu \mathrm{G}$ system (as shown in Fig 5) and the utility where the storage system provides the power for sag compensation through the DC link.

\section{b. Reverse-flow mode}

When the available DG power becomes higher than the required load demand, the extra energy is transferred to the grid and storage and this is termed the reverse-flow mode. At this stage, the grid current becomes out of phase with the voltage at PCC. Fig 7 shows the performance of the system when DG current becomes $1.5 I_{\text {loadf }}$ at $1.75 \mathrm{sec}$ and a $30 \%$ sag is also applied at $1.85 \mathrm{sec}$.

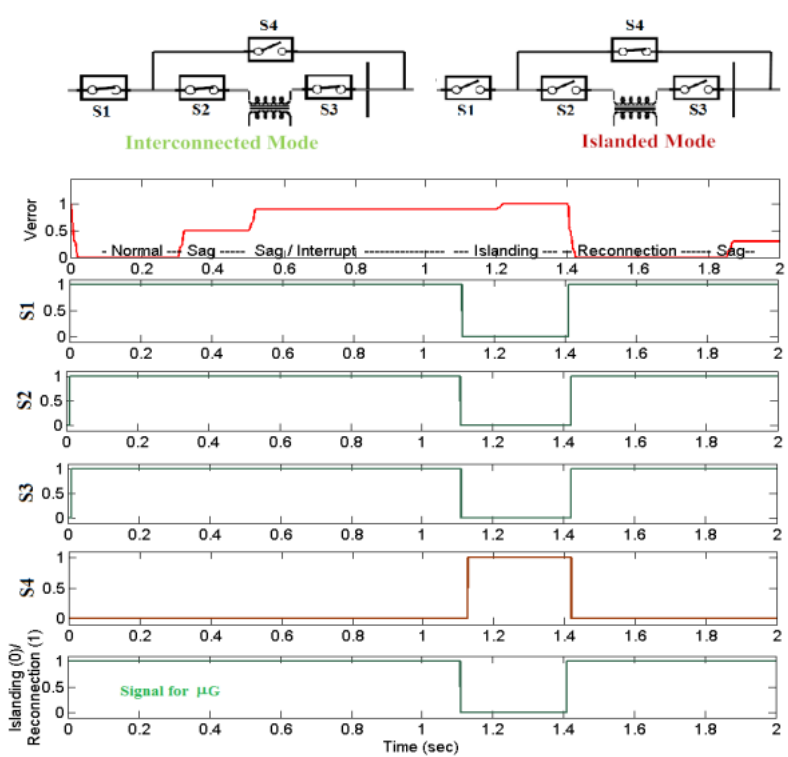

(a)

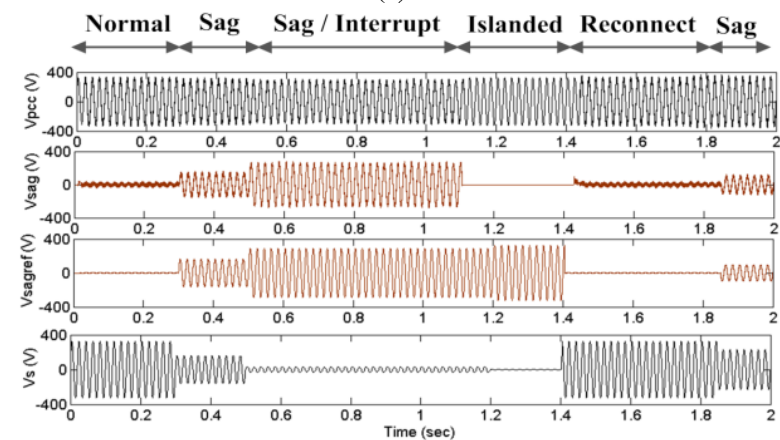

(b)

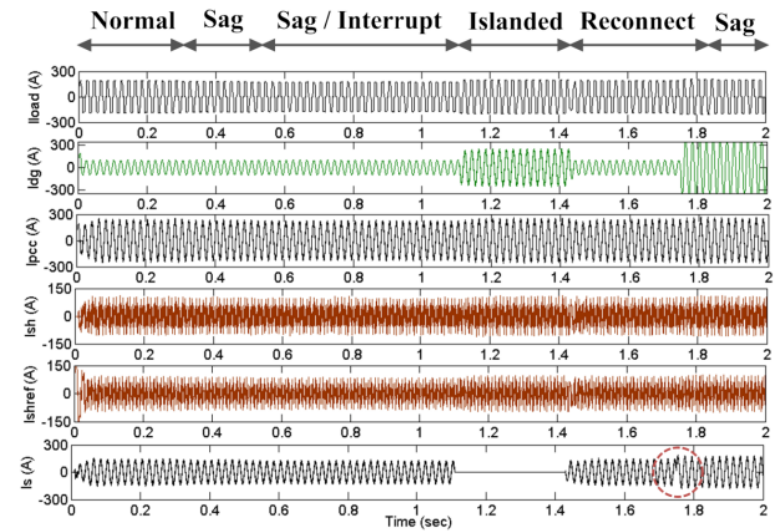

(c)

Fig 5: (a) Switching positions during the operation; (b) voltage and (c) current waveforms at difference conditions and positions in the network.

\section{B. Islanded Mode}

According to the Sig-IsD method, the $\mathrm{APF}_{\mathrm{se}}$ compensates the sag for up to $0.6 \mathrm{sec}$ ( 30 cycles) and then the system goes into islanded mode. A utility disconnection is applied at $1.11 \mathrm{sec}$ just after completing the 30 cycle count and then detecting the zero crossing of $V_{\text {sag-ref }}$ where $\mathrm{S} 1, \mathrm{~S} 2$ and $\mathrm{S} 3$ are opened. This is depicted in Fig 8. At disconnection, the $\mu \mathrm{G}$ operates in islanded mode. At this stage, if the available DG power is lower than the load demand, the required power is supplied by the storage. If the DG power is higher than the load, then 
the additional power goes to the storage. The $\mathrm{APF}_{\text {sh }}$ still performs the compensation of non active power. Therefore, DG converter does not need to be disconnected or change the control strategy (supply only the fundamental active power) to supply power to the load.

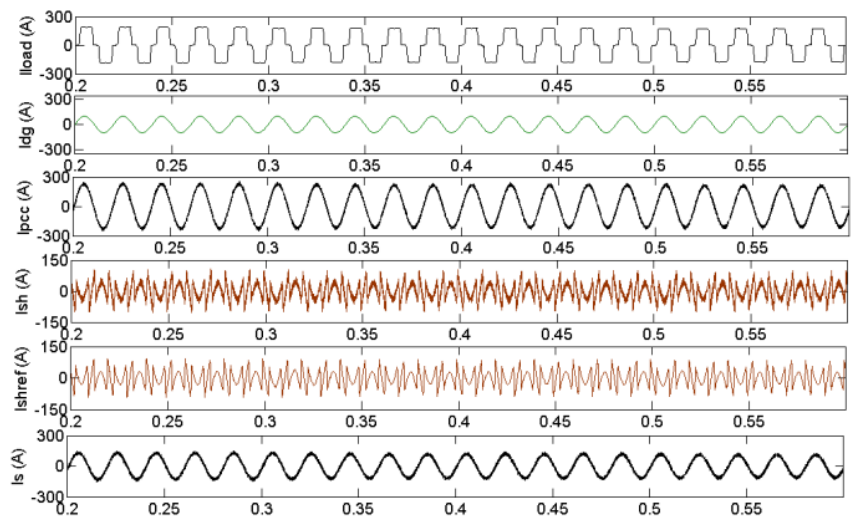

(b)

Fig 6: Performance of $\mathrm{APF}_{\text {sh }}$ in interconnected and forward flow mode

Fig 8 shows the performance of the proposed $\mathrm{UPQC}_{\mu \mathrm{G}}$ during 1.0 to $1.2 \mathrm{sec}$ where the islanding is detected just immediately after $1.1 \mathrm{sec}$ at zero crossing detection. The islanding mode is observed between 1.11 and $1.405 \mathrm{sec}$. During this period the $\mathrm{APF}_{\mathrm{se}}$ is disconnected, as shown in Fig 8(b) where $V_{\text {sag }}=0$, utility current become zero, as shown in Fig 8(c). The $\mathrm{APF}_{\text {sh }}$ continues to operate, as shown in Fig $8(\mathrm{c})$, and the load demand is met by the DG with the storage unit.

\section{Reconnection}

Fig 9(a) shows the different signals for the reconnection process based on the Sig-SynRec method showed in Fig 4. To check the performance of the reconnection process for the worst condition, the utility grid $\left(V_{S}\right)$ is powered on at 1.405 sec where the magnitude is at a maximum, as shown by the red circle in Fig 9(b). Zero crossing detection is also shown. The DG unit sends a reconnection signal, to the $\mathrm{UPQC}_{\mu \mathrm{G}}$ unit. Based on the logic given in Fig 11, the actual switch S1 is activated at $1.43 \mathrm{sec}$ and the $V_{\text {sag }}$ starts operation, as shown by the red circle in Fig 9(b). S2 and S3 are activated after the synchronization by the DG unit. S4 is disconnected simultaneously at $1.44 \mathrm{sec}$. This simple algorithm with a combined logic gate ensures the utility connects with the $\mu \mathrm{G}$ smoothly after the utility system is restored.

Fig 9(b) shows that the $\mathrm{APF}_{\text {se }}$ unit is immediately reactivated when the grid voltage is available at $1.405 \mathrm{sec}$ but it starts operation when the S2 and S3 switches are closed at $1.43 \mathrm{sec}$. It is expected that, according to the smooth reclosing condition, no power flow will occur at the point of reclosing. The switching is carried out successfully within the limiting condition as shown in Fig 9(c). The circle at $1.43 \mathrm{sec}$ for $I_{d g}$ and $I_{s}$ in Fig 9(c) indicates the smooth transition from islanded to interconnected mode. DG converter also changes its control from voltage to current control mode but only transfers the active fundamental current. The performance of the $\mathrm{APF}_{\mathrm{sh}}$ is also uninterrupted during the transition period.

\section{Power Flow}

The power flow diagram is shown in Fig 10 for the complete simulation time where the green line represent the active power $(\mathrm{P})$ and red line (dash) for reactive and harmonic power $(\mathrm{QH})$. This also validates the operation and performance of the $\mathrm{APF}_{\mathrm{se}}$ and $\mathrm{APF}_{\mathrm{sh}}$ part of the proposed $\mathrm{UPQC}_{\mu \mathrm{G}}$ along with the islanding detection and reconnection.

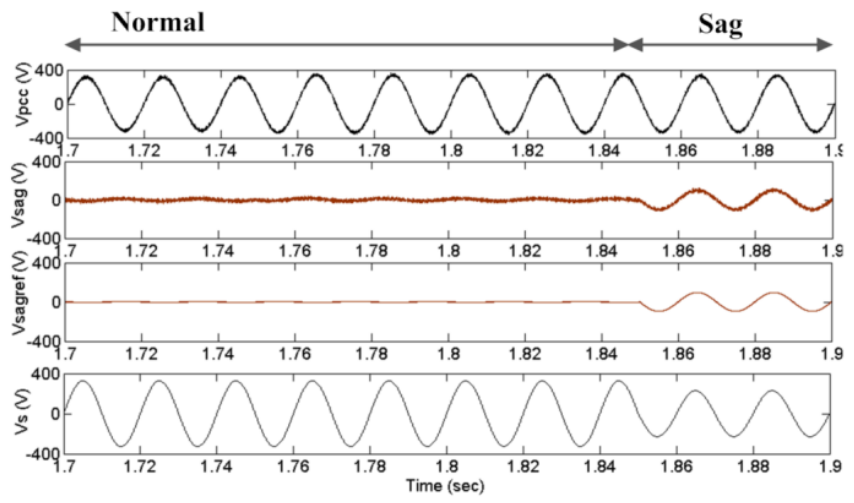

(a)

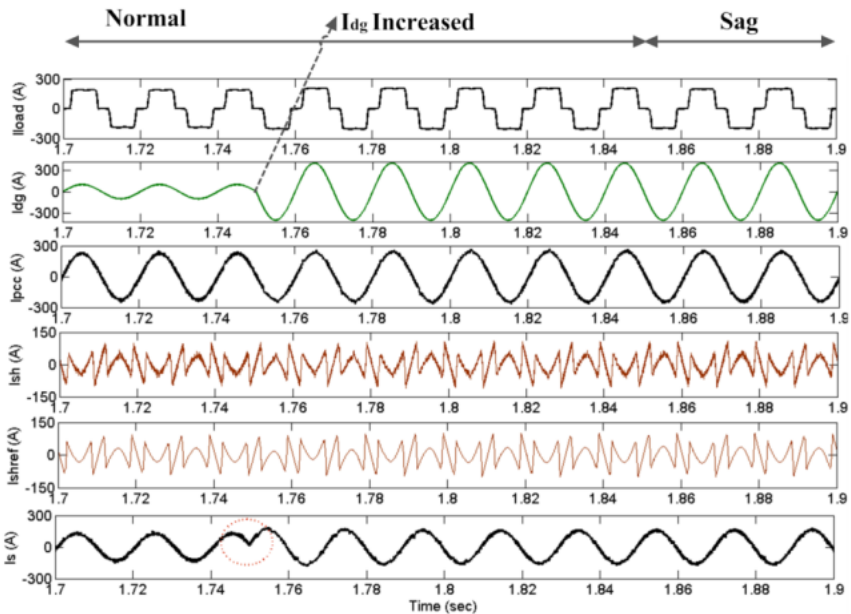

(b)

Fig 7: Performance; a) $\mathrm{APF}_{\text {se }}$; b) $\mathrm{APF}_{\text {sh }}$; interconnected and reverse flow

\section{CONCLUSION}

This paper describes a new placement and integration technique of the $\mathrm{UPQC}_{\mu \mathrm{G}}$ in the grid connected $\mu \mathrm{G}$ condition. The simulation has been performed in MATLAB. The results show that the proposed system can compensate the voltage disturbance at the $\mathrm{PCC}$, the reactive and harmonic current compensation of the load that could inject at the PCC during the interconnected mode. Performance of the $\mathrm{UPQC}_{\mu \mathrm{G}}$ is also observed in bi-directional power flow condition. During the islanded mode, the DG converter also only supplies the active power to the load and the shunt APF performs the reactive and harmonic power compensation. Therefore, the grid-tie DG converter does not need to be disconnected or change its control strategy to keep the $\mu \mathrm{G}$ operating during the islanding detection and operation in islanded mode. 


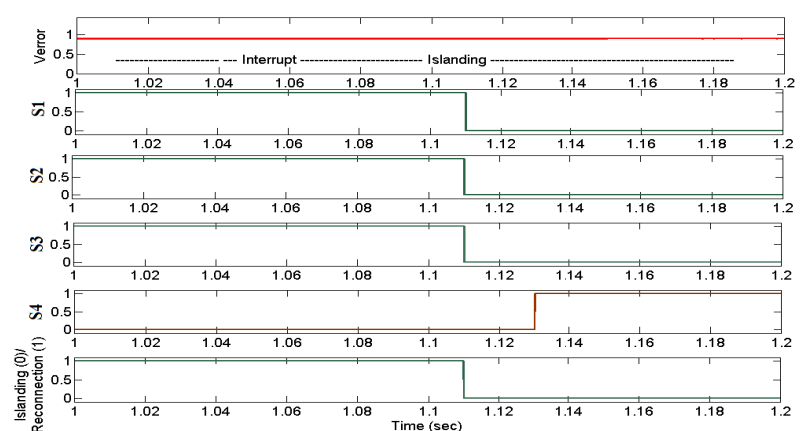

(a)

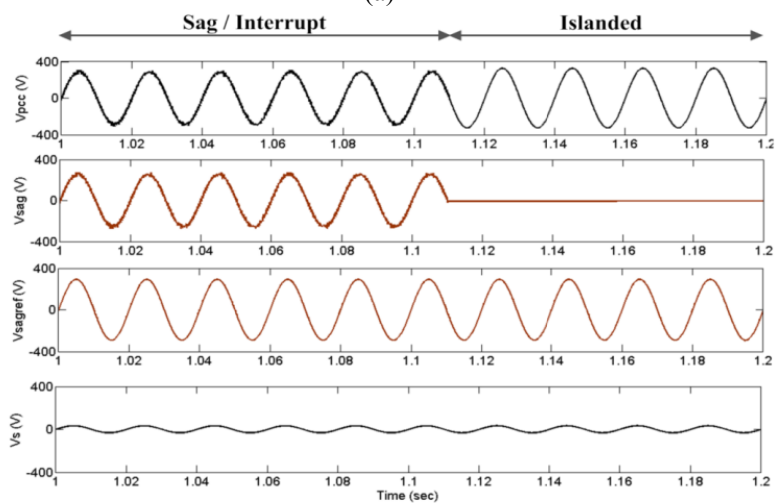

(b)

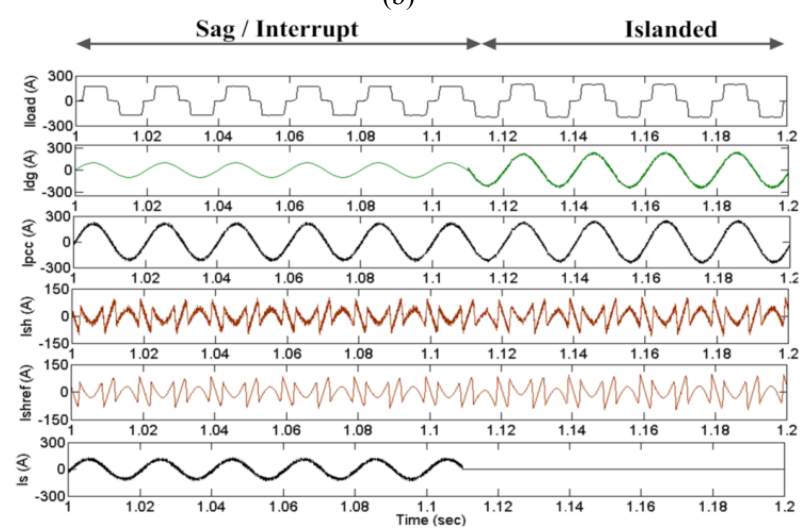

(c)

Fig 8: Performance -(a) switching, b) $\mathrm{APF}_{\mathrm{se}}$, c) $\mathrm{APF}_{\text {sh }}$ during islanded mode.

\section{REFERENCES}

[1] S. K. Khadem, M Basu and M F Conlon, UPQC for Power Quality Improvement in DG Integrated Smart Grid Network - A Review, International Journal of Emerging Electric Power Systems, Vol. 13(1), 2012, Art 3

[2] IEEE 1547, IEEE Standard for Interconnecting Distributed Resources with Electric Power Systems, 2003

[3] A Kahrobaeian, $Y$ Mohamed, Interactive distributed generation interface for flexible microgrid operation in smart distribution systems, IEEE Trans SE , vol.3(2), pp.295-305, 2012

[4] J M Guerrero, J Vasquez, J Matas, M Castilla, Hierarchical Control of Droop-Controlled AC and DC Microgrids-A General Approach Toward Standardization, IEEE Trans Industrial Electronics, vol.58, no.1, pp.158-172, Jan. 2011

[5] R Teodorescu, M Liserre, $\mathrm{P}$ Rodríguez, Grid Converters for Photovoltaic and Wind Power Systems, 1st Ed, Wiley IEEE, 2011

[7] A Kahrobaeian, $Y$ Mohamed, Interactive distributed generation interface for flexible microgrid operation in smart distribution systems, IEEE Trans SE , vol.3(2), pp.295-305, 2012

[6] H. Kim, T. Yu, S. Choi, Indirect current control algorithm for utility interactive inverters in distributed generation systems, IEEE Trans. PE, vol. 23(3), pp. 1342-1347, May 2008.

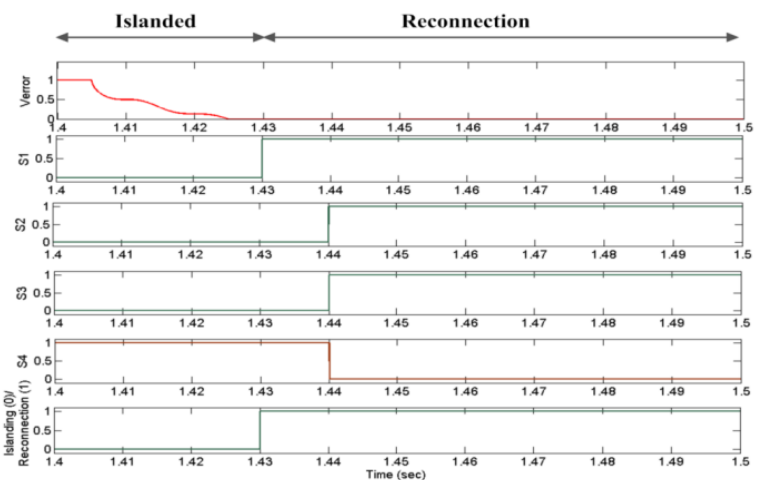

(a)

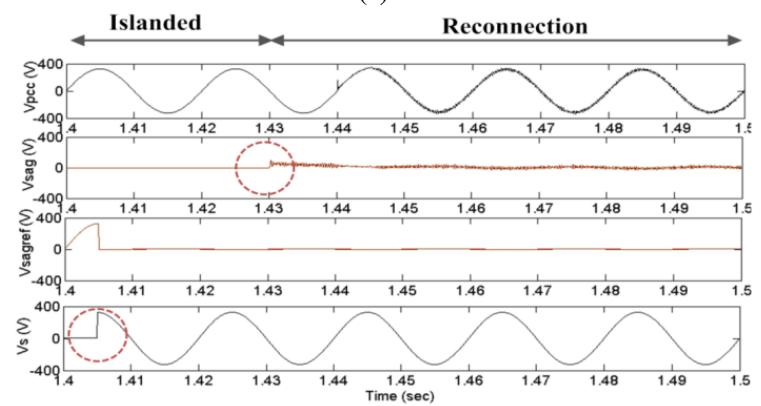

(b)

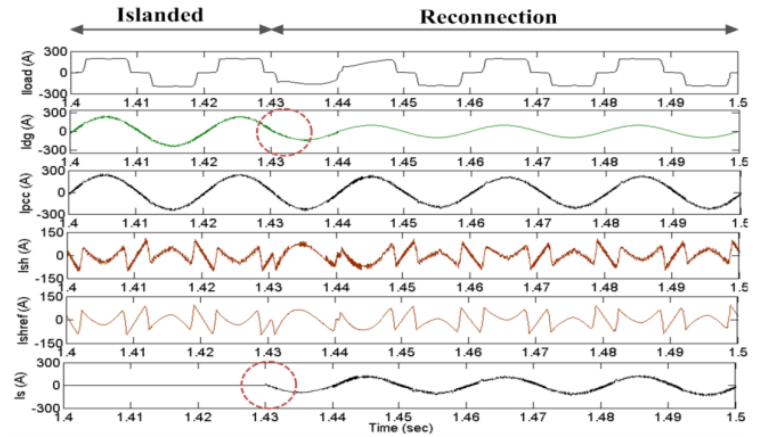

(c)

Fig 9: Reconnection -(a) switching, (b) $\mathrm{APF}_{\text {se }}$; (c) $\mathrm{APF}_{\text {sh }}$

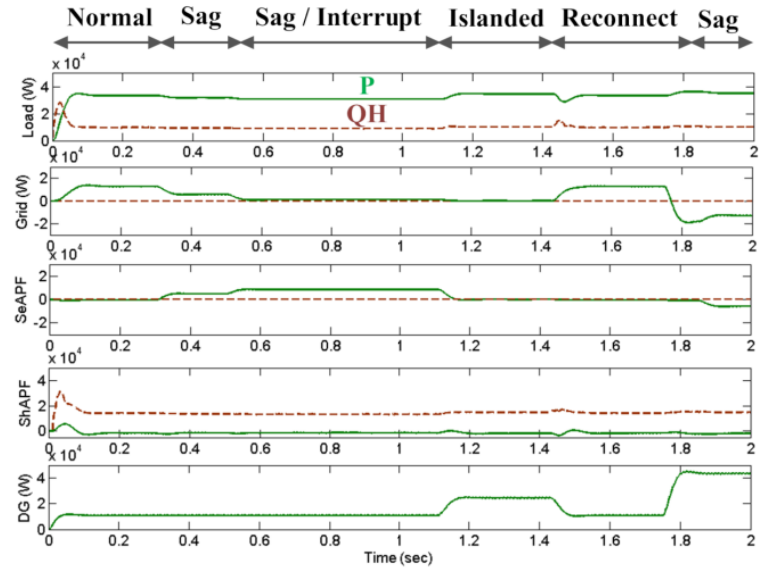

Fig 10: Power flow during the simulation time

[8] Z Yao, L Xiao, Y Yan, Seamless transfer of single-phase grid interactive inverters between grid connected and stand-alone modes, IEEE Trans. PE,vol.25(6), pp.1597-1603, 2010

[9] M Brenna, R Faranda, A New Proposal for Power Quality and Custom Power Improvement: OPEN UPQC, IEEE Trans Power Delivery, Vol. 24(4), 2009, pp. 2107-2116 